\title{
COVID-19 pandemic and reasons to prioritize the needs of the health care system to ensure its sustainability: A scoping review from January to October 2020 (Review)
}

\author{
DIMITRIOS ANYFANTAKIS ${ }^{1}$, AIKATERINI E. MANTADAKI ${ }^{2}$, STYLIANOS MASTRONIKOLIS ${ }^{3}$, \\ DEMETRIOS A. SPANDIDOS ${ }^{4}$ and EMMANOUIL K. SYMVOULAKIS ${ }^{3}$ \\ ${ }^{1}$ Primary Care Setting, Primary Health Centre of Kissamos, 73400 Chania; ${ }^{2}$ Department of Social Medicine, \\ ${ }^{3}$ Clinic of Social and Family Medicine, Faculty of Medicine, ${ }^{4}$ Laboratory of Clinical Virology, \\ School of Medicine, University of Crete, 71500 Heraklion, Greece
}

Received May 1, 2021; Accepted June 29, 2021

DOI: $10.3892 / \mathrm{etm} .2021 .10471$

\begin{abstract}
The worldwide spread of severe acute respiratory syndrome coronavirus 2 (SARS-CoV-2) led the World Health Organization to characterize the pandemic as a public health emergency of international concern. National health care systems in countries during the initial surge of the pandemic were unable to handle the sanitarian crisis that had emerged. Thus, the prevention and control of future global health emergencies must be a priority. The present scoping review aimed to retrieve articles that summarize the current experience on issues related to historical knowledge, and epidemiology, clinical features and overall burden of SARS-CoV-2 on health care services. In summary, a comprehensive overview of the information that has been learnt during this period is presented in the current review. Furthermore, taking into account the global experience, the need for planning cohesive and functional health services before similar pandemic events occur in the future is highlighted. The next public health issue should be prevented rather than treated. In spite of the vaccination benefits, a number of sporadic cases of SARS-CoV-2infections will persist. Information collected remains relevant for appraising how similar threats can be faced in the future. Overall, collaborative health care plans need to be rethought to increase preparedness.
\end{abstract}

Correspondence to: Professor Emmanouil K. Symvoulakis, Clinic of Social and Family Medicine, Faculty of Medicine, University of Crete, Andrea Kalokerinou 13, Giofirakia, 71500 Heraklion, Greece E-mail: symvouman@yahoo.com

Key words: human coronavirus, coronavirus disease 2019, multidisciplinary health planning

\section{Contents}

1. Introduction

2. Epidemiological features

3. Viral transmission patterns

4. Symptoms and disease presentation

5. Diagnosis

6. Discussion

7. Conclusions

\section{Introduction}

The history of coronaviruses begins when human coronaviruses (HCoVs), hitherto unnamed, were first characterized in the mid-1960s (1). They are large enveloped, positive-strand RNA viruses of the family Coronaviridae and are classified on four main subgroups [229E (alpha coronavirus); NL63 (alpha coronavirus); OC43 (beta coronavirus); HKU1 (beta coronavirus) $(1,2)$. These account for 10 to $30 \%$ of upper respiratory tract infections in adults (3). However, towards the end of 2002 and in 2013, two novel zoonotic HCoVs, namely severe acute respiratory syndrome coronavirus (SARS-CoV) and Middle East Respiratory Syndrome coronavirus (MERS-CoV), respectively were recognized as potentially lethal pathogens (2).

The outbreak of the SARS-CoV-1 began in southern China in 2002 and was transmitted worldwide through air travel, thus leading to a pandemic (2). SARS-CoV infection potentially led to atypical pneumonia and was clinically manifested by fever, malaise, lymphopenia and diarrhoea (2). MERS-CoV was first isolated in June 2012 in the Arabian Peninsula, producing pneumonia, acute kidney injury and multi-organ failure $(2,4)$. The horseshoe bat was assumed to be the primary host of SARS-COV, as well as MERS-CoV (2) and the dromedary camel may attribute as an intermediate reservoir towards human transmission for MERS-CoV $(2,3)$.

In December 2019, in the city of Wuhan, China, a novel virus caused severe lower respiratory tract illness with negative outcomes in terms of morbidity and mortality. On February 11, 2020, the pathogen was named SARS-CoV-2 
by the World Health Organization (WHO) and the associated disease, coronavirus disease-19 (COVID-19). Notably, although the novel SARS-CoV-2 and MERS-CoV share similar traits, including protein structuring, they have different genetic characteristics (5).

SARS-CoV-2, due to its expeditious transmission rate, rapidly spread worldwide, resulting in high rates of hospitalization and intensive care unit admissions and was thereby declared by the WHO as a global health emergency (6). Experience from countries during the first surge of the outbreak highlighted the weakness of health care services to combat the disease. The present study aimed to review certain historical information and the main topics related to COVID-19 conducting a search in PubMed between January 2020 and October 2020, in English language, by summarizing available evidence on its epidemiology trends, clinical features and overall burden on health care services. Although numerous issues of this rapidly evolving virus are known and some remain unanswered, it is aspired that the present scoping review will provide a comprehensive overview of what has been distilled as experience, providing a plausible reasoning for the need of multidisciplinary health service planning.

\section{Epidemiological features}

On December 29, 2019, four patients with acute respiratory syndrome of unknown origin were identified in Wuhan City, Hubei Province, China (7,8). A large local seafood and animal market in Wuhan was the only common spatial feature that linked these cases (7-9). Shortly thereafter, a human-to-human transmission via close contact (6) and no history of visiting Wuhan was confirmed; a significant proportion of infections also occurred among health care professionals $(7,9)$. The direct contact link with the Wuhan seafood market receded as the pandemic spread further $(8,10)$. On January 15, 2020 , the first lethal case from Wuhan was reported (6). As the pandemic evolved, it was observed that COVID-19 presented a relatively low mortality, but high infectivity (11). The assumed case fatality ratios varied across different countries. A high mortality rate was observed mainly in critically ill patients (12) and up to 5\% of COVID-19 cases were considered critical, implicating immune system dysregulation, possibly driven by a cytokine over-reaction (13).

Notably, the European region was more severely affected than the South-East Asian and African regions, which recorded lower morbidity and mortality rates (14). Additionally, BaHammam et al indicated a wide variability as regards the Eastern Mediterranean region, which may be attributed to differentiation in genetics, environment or resources (15).

Adult patients of all ages were infected, with fewer cases reported among children and infants $(7,16)$. The median patient age initially was 59 years, ranging from 51 to 89 years (7). Concerning the early-age infection distribution rate, this was depicted as follows: Those aged $\leq 39$ years, $10 \%$; 40-49 years, $22 \%$; 50-59 years, 30\%; 60-69 years, 22\%; and those aged $\geq 70$ years, $15 \%$ (17).

Asymptomatically infected patients are considered to contribute to the spread of the disease (18). Epidemiological data suggested that the male sex was more susceptible to COVID-19 (approximately 6 out of 10 cases are males) (7).
Those of non-Caucasian ethnicity, with obesity, epilepsy (19), individuals with chronic pulmonary disease (20), minorities, Hispanics and African Americans (21) were also more vulnerable to infection. Moreover, individuals of African origin, Asian and minority ethnic populations were more likely to be admitted to hospital and to succumb to the COVID-19 infection at a younger age (22). Initial observations supported a lower standardised incidence among individuals with HIV (23), an element that still remains debatable, while there is a hypothesis that beta-thalassemia patients seem to have a level of immunity protection (24). Immuno-compromised patients with hepatic and renal insufficiency, and co-morbidities have also been considered to be at a high risk of infection (25), thus warranting closer monitoring.

The robust infectivity and pathogenicity that COVID-19 presents maybe related to the affinity between SARS-CoV-2 $\mathrm{S}$ protein and the pertinent target cell angiotensin-converting enzyme 2 (ACE-2), which seems to be 10-20-fold stronger than that of SARS (26). When de-codifying this information, one can expect that a disproportionate care demand from a number of susceptible patients and at a 'condensed' time period can justify peaks of 'pressure' on health care systems overtime. Nevertheless, differences in infectivity, susceptibility, immune response and severity have been reported, and attributed to viral mutations (27), host-genetic variants (28) (40 genes identified for susceptibility and severity) (29), and 76 distinct genomic clusters (30).

\section{Viral transmission patterns}

The incubation period for COVID-19 ranges from 1 to 14 days (31), with a median of 5.2 days $(7,32)$. A study on181 confirmed cases of COVID-19 outside Wuhan, China reported that more than 9 out of 10 infected individuals presented symptoms within 11.5 days of infection (33). However, a previous case report suggested a longer incubation period that may extend up to 24 days (31).

Various main transmission routes have been reported for COVID-19 (8). These include transmission through inhalation or ingestion of large trans-respiratory droplets (airborne transmission) produced when an infected individual, coughs or sneezes; through inhalation of a large dose of infected aerosols into the lungs in an enclosed environment; through contact with an infected surface or object and subsequently touching the eyes, nose and mouth $(8,32)$. The low detection of the virus by reverse transcription polymerase chain reaction (RT-PCR) from conjunctival fluids has been reported in the literature (34). Notwithstanding, viral transmission through ocular fluids (tears and secretions) remains debatable (35). The virus has also been isolated from stool, suggesting that the digestive system may be another potential transmission route (8). Furthermore, transmission through urine is possible, thus indicating that caution should be taken when treating patients (36).

The emerging need to understand the environmental and social dynamics influencing the transmission of the disease is evident. In this context, setting-specific transmission patterns have been estimated in order to investigate the likelihood of infection within a closed group. The SARs (Secondary Attack Rates, SARs) scoring in healthcare settings 
is approximately $0.6 \%$, while households and residential settings entail high SARs $(37,38)$. Thus, prevention is crucial, and it is the most fundamental aspect of the inhibition of viral entry (39).

\section{Symptoms and disease presentation}

Fever is the first symptom in the majority of cases accompanied by a dry cough $(40)$, myalgias and anorexia $(6,9)$. Dyspnoea and fatigue are also common $(41,42)$. As summarized in a recent systematic review, ocular manifestations maybe the first presenting symptom of infection (34). Other clinical features listed are headaches, bilateral cracking sounds (43), diarrhoea, sputum production, haemoptysis (9) and sore throat (44). Gastrointestinal symptoms have also been reported, which may precede respiratory symptoms or be the only clinical manifestation (45). In addition, cutaneous manifestations have been linked to COVID-19 infection (46). Body aches, back/neck pain, urination issues, dehydration, allergy-like symptoms and eye-related issues have been extracted through social media applications, using machine learning tools and recognized as potential manifestations of COVID-19 infection (47). Olfactory and taste sense dysfunction (anosmia, dysgeusia) are also prevalent in patients with COVID-19 (48); a loss of smell has also been identified as a COVID-specific symptom (49), mostly in Caucasian populations (27), being valuable signs for pre-test screening (50). The role of interleukin- 6 role has been related to the pathogenesis of chemosensitive impairment (51).

In a study among 72,314 COVID-19 cases reported to the Chinese Centre for Disease Control and Prevention, a mild clinical course was reported in $81 \%$ (absent or mild pneumonia), severe in 14\% (hypoxia, dyspnoea, $>50 \%$ lung involvement within 24-48 h), critical in 5\% (respiratory failure, multi-organ dysfunction) and lethal in $2.3 \%$ of patients (52). The principal manifestations of COVID-19-induced pneumonia are related to restrictive ventilation disorder and small airway obstruction (53). Acute respiratory failure can likely occur (54) and its manifestation is extremely rapid in critically ill patients (55), affecting the prothrombotic state associated with elevated morbidity and mortality (56). Asymptomatic infections have been reported as common (52). However, the majority of infected individuals will not remain asymptomatic during the whole infection phase (18). Additionally, symptomatic COVID-19 disease has been shown to be more prevalent in males, and a potential interaction with smoking and alcohol consumption has been reported (57). A potential neuro-invasive role of COVID-19 has also been documented (58). Various pathophysiological mechanisms have been proposed for this association, including direct trans-neural penetration through the olfactory bulb, blood circulation pathways and neuronal pathways. Therefore, intra-cerebral infection symptoms such as headache, epilepsy, vomiting and disturbed consciousness may manifest in patients with COVID-19 infection at onset (59).

\section{Diagnosis}

A combination of disease history, clinical manifestations, laboratory examinations and computed tomography (CT) imaging is necessary to articulate an accurate diagnosis, contemplating the possible early accuracy weakness of RT-PCR (32). Nonetheless, a more reliable, final diagnosis should be based on a conjunctive examination of RT-PCR testing and CT screening (60). Laboratory abnormalities may include lymphopenia (44), the elevation of lactate dehydrogenase levels, a prolonged prothrombin time (31) and the elevation of aspartate aminotransferase levels (44).

Radiography and thoracic CT are abnormal in a number of patients. The majority of scanned patients present bilateral pulmonary involvement, with ground-glass infiltrates and patchy shadows (6). Other major CT findings include the involvement of the left lower lobe, sub-pleural distribution of lesions (61), vascular enlargement and interlobular septal thickening (62). It is proposed that a concurrent observation of ground glass opacity and other manifestations of viral pneumonia in a CT scan can competently detect COVID-19 infection (60). However, according to Salameh et al, a chest CT scan is sensitive, although not specific for the diagnosis of COVID-19, being unable to differentiate from other respiratory diseases (63). Mondoni et al indicated that bronchoscopy represents a further option, useful and safe technique to opt for when nasopharyngeal swabs are negative, as risk of transmission to healthcare workers is low, with strict safety procedures (64). Another option that can be used to assess COVID-19 pneumonia severity (65) is lung ultrasound, which is radiation-free, flexible, cost-effective and limits hospital transmission risks (bed-side performance) (66). An increased likelihood of COVID-19 infection has been associated with anosmia, bilateral B lines on lung ultrasonography (67) and incidences of shortness of breath (68).

As previously mentioned, acute respiratory distress syndrome (ARDS)is the most cited common complication of COVID-19 infection, as reviewed by Xie et al (54). Patients infected with COVID-19 also have a higher risk of arrhythmias, which constitute the second most common complication (69). Furthermore, severe COVID-19 infection has been linked to increased blood glucose levels (70). Another life-threatening condition concomitant to COVID-19, mostly severe infection, is the development of acute ischemic stroke (71), presumably triggered by hypercoagulability. Likewise, an exaggerated risk of venous thromboembolism (72), venous and arterial (73), pulmonary (74) and thromboembolic complications (75) is prevalent in COVID-19 patients. Acute kidney impairment is another major reported complication affecting the function of the kidneys post-infection (76), while liver injury and impaired function are also not uncommon (77). Several disorders affecting the central nervous system have been registered in the literature, including meningoencephalitis, encephalopathy, seizures and neuropsychiatric complications (78), as well as peripheral complications, including Guillain-Barré and Miller-Fischer syndrome (58), insinuating a pathogenic link to COVID-19 infection (79).

\section{Discussion}

Synthesizing the lived experience, COVID-19 is a highly infectious disease that triggers diagnostic capacity, preventive and supportive care, health personnel and system resources, society and economy, globally and persistently. The COVID-19 outbreak continues at an exaggerated rhythm, recording high 
infection rates across the planet $(14,52)$. In the European region, a number of countries faced a significant burden due to the incapacity of the health care services to sustain the massive influx of infected patients to hospital and emergency departments (80-82). Taking into account the multi-setting care disease complexity, difficulties in curbing the burden of complications were attributed to the traditional fragmentation and decentralization of health care services, weak national coordination, limited ability to implement timely interventions and difficulties encountered with medical equipment shortage (80).

Although some safe and effective vaccines have been developed, 'collective' immunity demands time and effort; a targeted antiviral treatment remains to be developed. Therefore, public health policymakers have suggested the prolonged implementation of traditional measures capable of interrupting person to person transmission. Such measures include isolation (separation of ill individuals), quarantine (restriction of persons who are presumed to have been exposed to the virus but are not yet ill) and community containment (cancellation of public gatherings, school closures; working from home) $(52,83)$.

Secondary care at hotspots of outbreak have often failed to remain operational. Healthcare personnel faced extremely heavy workloads. In an Italian hospital, within $24 \mathrm{~h}$ following the ICU admission of patient 1 , another 36 cases were identified, without obvious links, and a clustering effect was hypothesized (84). Initially, the care and transport of patients facilitated COVID-19 transmission to health care workers, rendering many of them vectors, which also contributed to the spread of the disease (85).

The development of a resilient, yet properly articulated health care system (86) appears of critical importance in order to handle similar future public health and health care disasters (52). COVID-19 is a multifactorial phenomenon, whose determinants include social, political and economic components (87). The long-term effects of COVID-19 have not been emanated yet. Significant cognitive post-infection deficits have been observed (88) and mental health aspects are possibly undermined $(89,90)$. Thus, a multidisciplinary response to control this durable crisis is of utmost importance. Routine everyday health care services have to be further supported during periods of public health emergency and patients should be encouraged to visit emergency departments for severe symptoms (91), particularly when telehealth care faces practical limitations. Furthermore, public health authorities have to harmonically collaborate with academic experts, health care workers in primary, secondary and tertiary care, in order to interlink horizontal and vertical actions in a multifaceted manner.

A community-focused care is necessary in order to diminish hospital care provision load and guarantee a more sustainable health care system longitudinally. Citizen compliance and personal responsibility are important components of this 'puzzle'. Close monitoring at the home of suspected cases, and telemedicine techniques for infected individuals (92) that require isolation and extensive social tracing may decrease the risk of health care-associated transmission. Notwithstanding, obstacles to their application comprise mistrust issues, and stigmatization concerns (93), without excluding proper public health education.
The implementation of a global people-centred primary health care system, prepared to sustain potential pressure (86), although challenging, emerges as an important health policy priority (94). A long-term plan remains necessary for integrated, multidisciplinary, team-based and people-centred care (94). In summary, it appears that active communication and interconnection between primary, secondary and tertiary care to triage and handle cases with different severity through multidisciplinary care teams. Health planning should take individual and community health needs into account and utilize all available resources. Social and mental health issues deserve attention and viable routes of intervention. Preventive care should endorse modern educational content for health professionals and communities. Undergraduate and postgraduate curricula should be further focused on altruistic spirit and behavior in the context of care teams, which act in terms of good practice and trust.

Multi-discipline and multi-sector collaboration across countries and systems represent a complex 'equation' and parameters that deal with social and economic discomfort, human insecurity and ethics demand attention and global partnership. Best usage of our every resource has been revealed as essential to run this 'marathon'. Clinicians and researchers should work together by translating fragmented bio-clinical information to health care deliverables to re-feed clinical practice and hope. Professionals and teams should take into consideration that, in this case, any success story can save patients' lives and health systems by keeping services functional over time. In the meantime, health care professionals should offer the best of their good practice at different stages of care and solidarity at every moment.

\section{Conclusions}

Various measures have been recommended in a long-term perspective, such as an appropriate human resource plan able to enhance team integration with primary care professionals in mutual collaboration with specialists (94), the implementation of an operational e-communication (95) and coordination, by controlling peaks of care demand to avoid burdening of structures, a saturation of services and burning out of human resources. COVID-19 horizontally challenges economies, societies, academia and health systems and vertically triggers health system resistance. Collaborative care health planning is needed to be re-thought to neutralize any asymmetric global threat currently and in the future. In spite of the expected success of vaccination, a number of sporadic cases of COVID-19 infection will persist, being an affliction affecting humanity. Information collected remains relevant for appraising how we can deal with similar threats and be more prepared. The next public health's spread should be prevented rather than treated. We should be prepared and alert to fertilize the ground for a new spirit of collaboration to harvest global success.

\section{Acknowledgements}

The authors would like to thank Dr Constantine Vardavas (Department of Oral Health Policy in Epidemiology, Harvard School of Public Health, Boston, MA, USA) for language editing the manuscript. 


\section{Funding}

No funding was received.

\section{Availability of data and materials}

Not applicable.

\section{Authors' contributions}

DA and EKS conceived the idea for the present review, and prepared the first draft of the manuscript. DA, AEM, SM and EKS performed the literature search and made revisions to the text and content. DAS provided intellectual input and performed revisions to improve the clarity of the manuscript. Data authentication is not applicable. All authors have read and approved the final manuscript.

\section{Ethics approval and consent to participate}

Not applicable.

\section{Patient consent for publication}

Not applicable.

\section{Competing interests}

DAS is the Editor-in-Chief for the journal, but had no personal involvement in the reviewing process, or any influence in terms of adjudicating on the final decision, for this article. The other authors declare that they have no competing interests.

\section{References}

1. Hamre D and Procknow JJ: A new virus isolated from the human respiratory tract. Proc Soc Exp Biol Med 121: 190-193, 1966.

2. de Wilde AH, Snijder EJ, Kikkert $M$ and van Hemert MJ: Host factors in coronavirus replication. Curr Top Microbiol Immunol 419: 1-42, 2018.

3. Paules CI, Marston HD and Fauci AS: Coronavirus infections-more than just the common cold. JAMA 323: 707-708, 2020.

4. Zaki AM, van Boheemen S, Bestebroer TM, Osterhaus AD and Fouchier RA: Isolation of a novel coronavirus from a man with pneumonia in Saudi Arabia. N Engl J Med 367: 1814-1820, 2012.

5. Zhu N, Zhang D, Wang W, Li X, Yang B, Song J, Zhao X, Huang B, Shi W, Lu R, et al: A novel coronavirus from patients with pneumonia in China, 2019. N Engl J Med 382: 727-733, 2020.

6. Yi Y, Lagniton PNP, Ye S, Li E and Xu RH: COVID-19: What has been learned and to be learned about the novel coronavirus disease. Int J Biol Sci 16: 1753-1766, 2020.

7. Li Q, Guan X, Wu P, Wang X, Zhou L, Tong Y, Ren R, Leung KSM, Lau EHY, Wong JY, et al: Early transmission dynamics in Wuhan, China, of novel coronavirus-infected pneumonia. N Engl J Med 382: 1199-1207, 2020.

8. Adhikari SP, Meng S, Wu YJ, Mao YP, Ye RX, Wang QZ, Sun C, Sylvia S, Rozelle S, Raat H and Zhou H: Epidemiology, causes, clinical manifestation and diagnosis, prevention and control of coronavirus disease (COVID-19) during the early outbreak period: A scoping review. Infect Dis Poverty 9: 29, 2020.

9. Huang C, Wang Y, Li X, Ren L, Zhao J, Hu Y, Zhang L, Fan G, $\mathrm{Xu}$ J, Gu X, et al: Clinical features of patients infected with 2019 novel coronavirus in Wuhan, China. Lancet 395: 497-506, 2020.

10. Wang C, Horby PW, Hayden FG and Gao GF: A novel coronavirus outbreak of global health concern. Lancet 395: 470-473, 2020 .
11. Bai YX, Xu YH, Wang X, Sun C, Guo Y, Qiu S and Ma KW: Advances in SARS-CoV-2: A systematic review. Eur Rev Med Pharmacol Sci 24: 9208-9215, 2020.

12. Shah S, Shah K, Patel SB, Patel FS, Osman M, Velagapudi P, Turagam MK, Lakkireddy D and Garg J: Elevated D-Dimer levels are associated with increased risk of mortality in COVID-19: A systematic review and meta-analysis. Cardiol Rev 28: 295-30, 2020.

13. Bordallo B, Bellas M, Cortez AF, Vieira M and Pinheiro M: Severe COVID-19: What have we learned with the immunopathogenesis?. Adv Rheumatol 60: 50, 2020.

14. WHO: Coronavirus disease 2019 (COVID-19) situation reports. https://www.who.int/emergencies/diseases/novelcoronavirus-2019/situation-reports. Accessed July 20, 2021.

15. BaHammam AS, Bindayna KM, Joji RM, Jahrami H, Faris MAE and Bragazzi NL: Outcomes of COVID-19 in the Eastern Mediterranean region in the first 4 months of the pandemic. Saudi Med J 41: 907-915, 2020.

16. Hamid S, Mir MY, and Rohela GK: Novel coronavirus disease (COVID-19): a pandemic (epidemiology, pathogenesis and potential therapeutics). New Microbes New Infect. 35: 100679, 2020.

17. Chen N, Zhou M, Dong X, Qu J, Gong F, Han Y, Qiu Y, Wang J, Liu Y, Wei Y, et al: Epidemiological and clinical characteristics of 99 cases of 2019 novel coronavirus pneumonia in Wuhan, China: A descriptive study. Lancet 395: 507-513, 2020.

18. Buitrago-Garcia D, Egli-Gany D, Counotte MJ, Hossmann S, Imeri H, Ipekci AM, Salanti G and Low N: Occurrence and transmission potential of asymptomatic and presymptomatic SARS-CoV-2 infections: A living systematic review and meta-analysis. PLoS Med 17: e1003346, 2020.

19. Cabezudo-García P, Ciano-Petersen NL, Mena-Vázquez N, Pons-Pons G, Castro-Sánchez MV and Serrano-Castro PJ: Incidence and case fatality rate of COVID-19 in patients with active epilepsy. Neurology 95: e1417-e1425, 2020.

20. Elias M, Pievani D, Randoux C, Louis K, Denis B, Delion A, Le Goff O, Antoine C, Greze C, Pillebout E, et al: COVID-19 infection in kidney transplant recipients: Disease incidence and clinical outcomes. J Am Soc Nephrol 31: 2413-2423, 2020.

21. Wang Z, Zheutlin A, Kao YH, Ayers K, Gross S, Kovatch P, Nirenberg S, Charney A, Nadkarni G, De Freitas JK, et al: Hospitalised COVID-19 patients of the Mount sinai health system: A retrospective observational study using the electronic medical records. BMJ Open 10: e040441, 2020.

22. Patel A, Abdulaal A, Ariyanayagam D, Killington K, Denny SJ, Mughal N, Hughes S, Goel N, Davies GW, Moore LSP and Charani E: Investigating the association between ethnicity and health outcomes in SARS-CoV-2 in a London secondary care population. PLoS One 15: e0240960, 2020.

23. Inciarte A, Gonzalez-Cordon A, Rojas J, Torres B, de Lazzari E, de la Mora L, Martinez-Rebollar M, Laguno M, Callau P, Gonzalez-Navarro A, et al: Clinical characteristics, risk factors, and incidence of symptomatic coronavirus disease 2019 in a large cohort of adults living with HIV: A single-center, prospective observational study. AIDS 34: 1775-1780, 2020.

24. Lansiaux E, Pébaÿ PP, Picard JL and Son-Forget J: COVID-19: Beta-thalassemia subjects immunised?. Med Hypotheses 142: 109827, 2020.

25. Dhar D and Mohanty A: Gut microbiota and Covid-19-possible link and implications. Virus Res 285: 198018, 2020.

26. Lu R, Zhao X, Li J, Niu P, Yang B, Wu H, Wang W, Song H, Huang B, Zhu N, et al: Genomic characterisation and epidemiology of 2019 novel coronavirus: Implications for virus origins and receptor binding. Lancet 395: 565-574, 2020.

27. von Bartheld CS, Hagen MM and Butowt R: Prevalence of chemosensory dysfunction in COVID-19 patients: A systematic review and meta-analysis reveals significant ethnic differences. ACS Chem Neurosci 11: 2944-2961, 2020.

28. Di Maria E, Latini A, Borgiani P and Novelli G: Genetic variants of the human host influencing the coronavirus-associated phenotypes (SARS, MERS and COVID-19): Rapid systematic review and field synopsis. Hum Genomics 14: 30, 2020.

29. Elhabyan A, Elyaacoub S, Sanad E, Abukhadra A, Elhabyan A and Dinu V: The role of host genetics in susceptibility to severe viral infections in humans and insights into host genetics of severe COVID-19: A systematic review. Virus Res 289: 198163, 2020.

30. Seemann T,Lane CR, Sherry NL, Duchene S, Gonçalves da Silva A, Caly L, Sait M, Ballard SA, Horan K, Schultz MB, et al: Tracking the COVID-19 pandemic in Australia using genomics. Nat Commun 11: 4376, 2020. 
31. Del Rio C and Malani PN: COVID-19-new insights on a rapidly changing epidemic. JAMA 323: 1339-1340, 2020.

32. Xu J, Ma XP, Bai L, Wang M, Deng W and Ning N: A systematic review of etiology, epidemiology, clinical manifestations, image findings, and medication of 2019 corona virus disease-19 in Wuhan, China. Medicine (Baltimore) 99: e22688, 2020.

33. Lauer SA, Grantz KH, Bi Q, Jones FK, Zheng Q, Meredith HR, Azman AS, Reich NG and Lessler J: The incubation period of coronavirus disease 2019 (COVID-19) from publicly reported confirmed cases: Estimation and application. Ann Intern Med 172: 577-582, 2020.

34. Ling XC, Kang EY, Lin JY, Chen HC, Lai CC, Ma DH and Wu WC: Ocular manifestation, comorbidities, and detection of severe acute respiratory syndrome-coronavirus 2 from conjunctiva in coronavirus disease 2019: A systematic review and meta-analysis. Taiwan J Ophthalmol 10: 153-166, 2020.

35. Aggarwal K, Agarwal A, Jaiswal N, Dahiya N, Ahuja A, Mahajan S, Tong L, Duggal M, Singh M, Agrawal R and Gupta V: Ocular surface manifestations of coronavirus disease 2019 (COVID-19): A systematic review and meta-analysis. PLoS One 15: e0241661, 2020.

36. Kashi AH, De la Rosette J, Amini E, Abdi H, Fallah-Karkan M and Vaezjalali M: Urinary viral shedding of COVID-19 and its clinical associations: A systematic review and meta-analysis of observational studies. Urol J 17: 433-441, 2020.

37. Koh WC, Naing L, Chaw L, Rosledzana MA, Alikhan MF Jamaludin SA, Amin F, Omar A, Shazli A, Griffith M, et al What do we know about SARS-CoV-2 transmission? A systematic review and meta-analysis of the secondary attack rate and associated risk factors. PLoS One 15: e0240205, 2020.

38. Brito CAA, Brito MCM, Martins THF, Brito CCM, Albuquerque MFM and Brito RCCM: Clinical laboratory and dispersion pattern of COVID-19 in a family cluster in the social-distancing period. J Infect Dev Ctries 14: 987-993, 2020.

39. Seyedpour S, Khodaei B, Loghman AH, Seyedpour N Kisomi MF, Balibegloo M, Nezamabadi SS, Gholami B, Saghazadeh A and Rezaei N: Targeted therapy strategies against SARS-CoV-2 cell entry mechanisms: A systematic review of in vitro and in vivo studies. J Cell Physiol 236: 2364-2392, 2021.

40. Li HY, Wang JW, Xu LW, Zhao XL, Feng JX and Xu YZ: Clinical analysis of 132 cases COVID-19 from Wuhan. Medicine (Baltimore) 99: e22847, 2020.

41. Sheleme T, Bekele F and Ayela T: Clinical presentation of patients infected with coronavirus disease 19: A systematic review. Infect Dis (Auckl) 13: 1178633720952076, 2020.

42. Alimohamadi $\mathrm{Y}$, Sepandi $\mathrm{M}$, Taghdir $\mathrm{M}$ and Hosamirudsari $\mathrm{H}$ Determine the most common clinical symptoms in COVID-19 patients: A systematic review and meta-analysis. J Prev Med Hyg 61: E304-E312, 2020.

43. Zayet S, Kadiane-Oussou NJ, Lepiller Q, Zahra H, Royer PY, Toko L, Gendrin V and Klopfenstein T: Clinical features of COVID-19 and influenza: A comparative study on Nord Franche-Comte cluster. Microbes Infect 22: 481-488, 2020.

44. Borges do Nascimento IJ, von Groote TC, O'Mathúna DP, Abdulazeem HM, Henderson C, Jayarajah U, Weerasekara I, Poklepovic Pericic T, Klapproth HEG, Puljak L, et al: Clinical, laboratory and radiological characteristics and outcomes of novel coronavirus (SARS-CoV-2) infection in humans: A systematic review and series of meta-analyses. PLoS One 15: e0239235, 2020

45. Pamplona J, Solano R, Soler C and Sabat M: Epidemiological approximation of the enteric manifestation and possible fecal-oral transmission in COVID-19: A preliminary systematic review. Eur J Gastroenterol Hepatol: Sep 17, 2020 (Epub ahead of print). doi: 10.1097/MEG.0000000000001934.

46. Singh H, Kaur H, Singh K and Sen CK: Cutaneous manifestations of COVID-19: A systematic review. Adv Wound Care (New Rochelle) 10: 51-80, 2021

47. Jeon J, Baruah G, Sarabadani S and Palanica A: Identification of risk factors and symptoms of COVID-19: Analysis of biomedical literature and social media data. J Med Internet Res 22: e20509, 2020.

48. Borsetto D, Hopkins C, Philips V, Obholzer R, Tirelli G, Polesel J and Boscolo-Rizzo P: Self-reported alteration of sense of smell or taste in patients with COVID-19: A systematic review and meta-analysis on 3563 patients. Rhinology 58: 430-436, 2020.

49. Makaronidis J, Mok J, Balogun N, Magee CG, Omar RZ, Carnemolla A and Batterham RL: Seroprevalence of SARS-CoV-2 antibodies in people with an acute loss in their sense of smell and/or taste in a community-based population in London, UK An observational cohort study. PLoS Med 17: e1003358, 2020.
50. Pang KW, Chee J, Subramaniam S and Ng CL: Frequency and clinical utility of olfactory dysfunction in COVID-19: A systematic review and meta-analysis. Curr Allergy Asthma Rep 20: 76, 2020.

51. Cazzolla AP, Lovero R, Lo Muzio L, Testa NF, Schirinzi A, Palmieri G, Pozzessere P, Procacci V, Di Comite M, Ciavarella D, et al: Taste and smell disorders in COVID-19 patients: Role of interleukin-6. ACS ChemNeurosci 11: 2774-2781, 2020.

52. Wu Z and McGoogan JM: Characteristics of and important lessons from the coronavirus disease 2019 (COVID-19) outbreak in China: Summary of a report of 72314 cases from the Chinese center for disease control and prevention. JAMA 323: 1239-1242, 2020.

53. Lv D, Chen X, Wang X, Mao L, Sun J, Wu G, Lin Z, Lin R, Yu J, Wu X and Jiang Y: Pulmonary function of patients with 2019 novel coronavirus induced-pneumonia: A retrospective cohort study. Ann Palliat Med 9: 3447-3452, 2020.

54. Xie Y, Wang Z, Liao H, Marley G, Wu D and Tang W: Epidemiologic, clinical, and laboratory findings of the COVID-19 in the current pandemic: Systematic review and meta-analysis. BMC Infect Dis 20: 640, 2020

55. Chen N, Li Y, Fan H, Tian A, Yuan H, Jiang Z, Yu Y, Ruan L, $\mathrm{Hu}$ P, Yue M, et al: Analysis of dynamic disturbance in blood coagulation function of patients with coronavirus disease 2019: A retrospective observational study. Medicine (Baltimore) 99: e22635, 2020.

56. Piazza G, Campia U, Hurwitz S, Snyder JE, Rizzo SM, Pfeferman MB, Morrison RB, Leiva O, Fanikos J, Nauffal V, et al: Registry of arterial and venous thromboembolic complications in patients with COVID-19. J Am Coll Cardiol 76: 2060-2072, 2020.

57. Abate BB, Kassie AM, Kassaw MW, Aragie TG and Masresha SA: Sex difference in coronavirus disease (COVID-19): A systematic review and meta-analysis. BMJ Open 10: e040129, 2020.

58. Orrù G, Conversano C, Malloggi E, Francesconi F, Ciacchini R and Gemignani A: Neurological complications of COVID-19 and possible neuroinvasion pathways: A systematic review. Int J Environ Res Public Health 17: 6688, 2020.

59. Wu Y, Xu X, Chen Z, Duan J, Hashimoto K, Yang L, Liu C and Yang C: Nervous system involvement after infection with COVID-19 and other coronaviruses. Brain Behav Immun 87: 18-22, 2020.

60. Hossein H, Ali KM, Hosseini M, Sarveazad A, Safari S and Yousefifard M: Value of chest computed tomography scan in diagnosis of COVID-19; a systematic review and meta-analysis. ClinTransl Imaging: Oct 12, 2020 (Epub ahead of print). doi: 10.1007/s40336-020-00387-9.

61. Muhammad SZ, Ahmed A, Shahid I, Khalid A, Menezes RG, Sheikh MU, Siddiqi TJ, Usman MS and Khosa F: Chest computed tomography findings in hospitalized COVID-19 patients: A systematic review and meta-analysis. Infez Med 28: 295-301, 2020.

62. Yang H, Lan Y, Yao X, Lin S and Xie B: The chest CT features of coronavirus disease 2019 (COVID-19) in China: A meta-analysis of 19 retrospective studies. Virol J 17: 159, 2020.

63. Salameh JP, Leeflang MM, Hooft L, Islam N, McGrath TA, van der Pol CB, Frank RA, Prager R, Hare SS, Dennie C, et al: Thoracic imaging tests for the diagnosis of COVID-19. Cochrane Database Syst Rev 9: CD013639, 2020.

64. Mondoni M, Sferrazza Papa GF, Rinaldo R, Faverio P, Marruchella A, D'Arcangelo F, Pesci A, Pasini S, Henchi S, Cipolla $\mathrm{G}$, et al: Utility and safety of bronchoscopy during the SARS-CoV-2 outbreak in Italy: A retrospective, multicentre study. Eur Respir J 56: 2002767, 2020.

65. Zieleskiewicz L, Markarian T, Lopez A, Taguet C, Mohammedi N, Boucekine M, Baumstarck K, Besch G, Mathon G, Duclos G, et al: Comparative study of lung ultrasound and chest computed tomography scan in the assessment of severity of confirmed COVID-19 pneumonia. Intensive Care Med 46: 1707-1713, 2020.

66. Iodice V, Pisaturo M, Fusco FM, Tambaro O, Parrella G, Di Flumeri G, Viglietti R, Pisapia R, Palmiero G,Bignardi E, et al: Use of lung ultrasound in COVID-19: Comparison with ultra-high-resolution computed tomography among 29 patients at 'D. Cotugno' hospital, Naples, Italy. Infez Med 28: 346-350, 2020.

67. Peyrony O, Marbeuf-Gueye C, Truong V, Giroud M, Rivière C, Khenissi K, Legay L, Simonetta M, Elezi A, Principe A, et al: Accuracy of emergency department clinical findings for diagnosis of coronavirus disease 2019. Ann Emerg Med 76: 405-412, 2020 . 
68. Panuganti BA, Jafari A, MacDonald B and DeConde AS Predicting COVID-19 incidence using Anosmia and other COVID-19 symptomatology: Preliminary analysis using google and twitter. Otolaryngol Head Neck Surg 163: 491-497, 2020.

69. Malaty M, Kayes T, Amarasekera AT, Kodsi M, MacIntyre CR and Tan TC: Incidence and treatment of arrhythmias secondary to coronavirus infection in humans: A systematic review. Eur J Clin Invest 51: e13428, 2021.

70. Chen J, Wu C, Wang X, Yu J and Sun Z: The impact of COVID-19 on blood glucose: A systematic review and meta-analysis. Front Endocrinol (Lausanne) 11: 574541, 2020

71. Valencia-Enciso N, Ortiz-Pereira M, Zafra-Sierra MP, Espinel-Gómez L and Bayona H: Time of stroke onset in coronavirus disease 2019 patients around the globe: A systematic review and analysis. J Stroke Cerebrovasc Dis 29: 105325, 2020

72. Nopp S, Moik F, Jilma B, Pabinger I and Ay C: Risk of venous thromboembolism in patients with COVID-19: A systematic review and meta-analysis. Res Pract Thromb Haemost 4: $1178-1191,2020$

73. Shah A, Donovan K, McHugh A, Pandey M, Aaron L, Bradbury CA, Stanworth SJ, Alikhan R, Von Kier S, Maher K, et al: Thrombotic and haemorrhagic complications in critically ill patients with COVID-19: A multicentre observational study. Crit Care 24: 561, 2020.

74. Monfardini L, Morassi M, Botti P, Stellini R, Bettari L, Pezzotti S Alì M, Monaco CG, Magni V, Cozzi A, et al: Pulmonary thromboembolism in hospitalised COVID-19 patients at moderate to high risk by wells score: A report from Lombardy, Italy. $\mathrm{Br}$ J Radiol 93: 20200407, 2020.

75. Di Minno A, Ambrosino P, Calcaterra I and Di Minno MND: COVID-19 and Venous Thromboembolism: A meta-analysis of literature studies. Semin Thromb Hemost 46: 763-771, 2020.

76. Nogueira SÁR, Oliveira SCS, Carvalho AFM, Neves JMC, Silva LSVD, Silva Junior GBD and Nobre MEP: Renal changes and acute kidney injury in covid-19: A systematic review. Rev Assoc Med Bras (1992) 66 (Suppl 2): S112-S117, 2020.

77. Chen S, Liu H, Li T, Huang R, Gui R and Zhang J: Correlation analysis of coagulation dysfunction and liver damage in patients with novel coronavirus pneumonia: A single-center, retrospective, observational study. Ups J Med Sci 125: 293-296, 2020

78. Almqvist J, Granberg T, Tzortzakakis A, Klironomos S, Kollia E, Öhberg C, Martin R, Piehl F, Ouellette R and Ineichen BV: Neurological manifestations of coronavirus infections-a systematic review. Ann ClinTransl Neurol 7: 2057-2071, 2020

79. Uncini A, Vallat JM and Jacobs BC: Guillain-Barré syndrome in SARS-CoV-2 infection: An instant systematic review of the first six months of pandemic. J Neurol Neurosurg Psychiatry 91 $1105-1110,2020$.

80. Armocida B, Formenti B, Ussai S, Palestra F and Missoni E: The Italian health system and the COVID-19 challenge. Lancet Public Health 5: e253, 2020.

81. Zach H, Hanová M and Letkovičová M: Distribution of COVID-19 cases and deaths in Europe during the first 12 peak weeks of outbreak. Cent Eur J Public Health 29: 9-13, 2021.

82. Mogi R and Spijker J: The influence of social and economic ties to the spread of COVID-19 in Europe. J Popul Res (Canberra): Apr 5, 2021 (Epub ahead of print). doi: https://doi.org/10.1007/ s12546-021-09257-1.
83. Cetron $\mathrm{M}$ and Simone P: Battling 21st-century scourges with a 14th-century toolbox. Emerg Infect Dis 10: 2053-2054, 2004

84. Grasselli G, Pesenti A and Cecconi M: Critical care utilization for the COVID-19 Outbreak in Lombardy, Italy: Early experience and forecast during an emergency response. JAMA 323 : $1545-1546,2020$.

85. Wang D, Hu B, Hu C, Zhu F, Liu X, Zhang J, Wang B, Xiang H, Cheng Z, Xiong Y, et al: Clinical characteristics of 138 Hospitalized patients with 2019 novel coronavirus-infected Pneumonia in Wuhan, China. JAMA 323: 1061-1069, 2020.

86. Symvoulakis EK, Sourvinos G, Spandidos DA and Lionis C: COVID-19 pandemic: Monitoring space-time data and learning from global experience. Exp Ther Med 20: 73, 2020.

87. Mendenhall E: The COVID-19 syndemic is not global: Context matters. Lancet 396: 1731, 2020.

88. Hampshire A, Trender W, Chamberlain SR, Jolly A, Grant EJ, Patrick F, Mazibuko N, Williams S, Barnby JM, Hellyer P and Mehta MA: Cognitive deficits in people who have recovered from COVID-19 relative to controls: An N=84,285 online study. MedRxiv: 2020.10.20.20215863, 2020; doi: https://doi.org/10.11 01/2020.10.20.20215863.

89. Amorim R, Catarino S, Miragaia P, Ferreras C, Viana V and Guardiano M: The impact of COVID-19 on children with autism spectrum disorder. Rev Neurol 71: 285-291, 2020.

90. Khan S, Siddique R, Li H, Ali A, Shereen MA, Bashir N and Xue M: Impact of coronavirus outbreak on psychological health. J Glob Health 10: 010331, 2020.

91. Jeffery MM,D'Onofrio G, Paek H, Platts-Mills TF, Soares WE III, Hoppe JA, Genes N, Nath B and Melnick ER: Trends in emergency department visits and hospital admissions in health care systems in 5 States in the first months of the COVID-19 pandemic in the US. JAMA Intern Med 180: 1328-1333, 2020.

92. Symvoulakis EK and Anyfantakis D: Primary care and the COVID-19 pandemic: Schrödinger's cat. ERJ Open Res 7: 00730-02020, 2021

93. Megnin-Viggars O, Carter P, Melendez-Torres GJ, Weston D and Rubin GJ: Facilitators and barriers to engagement with contact tracing during infectious disease outbreaks: A rapid review of the evidence. PLoS One 15: e0241473, 2020.

94. Lionis C, Symvoulakis EK, Markaki A, Petelos E, Papadakis S, Sifaki-Pistolla D, Papadakakis M, Souliotis K and Tziraki C: Integrated people-centred primary health care in Greece: Unravelling Ariadne's thread. Prim Health Care Res Dev 20: e113, 2019.

95. Lionis C, Petelos E, Papadakis S, Tsiligianni I, Anastasaki M, Angelaki A, Bertsias A, Mechili EA, Papadakaki M, Sifaki-Pistolla D and Symvoulakis E: Towards evidence-informed integration of public health and primary health care: Experiences from Crete. Public Health Panorama 04: 699-714, 2018. World Health Organization. Regional Office for Europe. https://apps. who.int/iris/handle/10665/324872.

This work is licensed under a Creative Commons Attribution-NonCommercial-NoDerivatives 4.0 International (CC BY-NC-ND 4.0) License. 